[white paper]

Diamond Open Access

\title{
Existem infinitos primos
}

Colaboração Matemática Aberta ${ }^{1}$

4 de Março de 2021

\section{Resumo}

Apresentamos a demonstração da infinitude dos primos de forma didática.

palavras-chave: teoria de números, infinitos primos

A versão mais atualizada deste artigo está disponível em https://osf.io/nz7q3/download

\section{Introdução}

1. Esses livros são excelentes referências para iniciar os estudos neste maravilhoso universo das demonstrações matemáticas [1-3].

2. Este é o segundo artigo da série Demonstrações Matemáticas [4].

3. Para estudar/revisar conceitos de Matemática Básica, veja [5-8].

\section{Teorema}

4. Existem infinitos primos.

${ }^{1}$ Todos os autores com suas afiliações aparecem no final deste artigo. 


\section{Prova por absurdo/contradição}

5. A prova por contradição consiste em assumir como FALSA a proposição que queremos provar e, ao chegar em um absurdo, concluímos que a proposição é verdadeira.

\section{Demonstração}

6. Utilizaremos (5) para provar (4).

7. Considere que exista um número finito de primos.

8. Seja $p_{1}, p_{2}, \ldots, p_{n}$ uma lista com todos os primos.

9. Seja $m=p_{1} p_{2} p_{3} \ldots p_{n}+1$.

10. Por exemplo, considerando $r<b$ e $r<c$, se dividirmos $a=b c+r$ por $b$ ou $c$, o resto será $r$.

11. De (9) e (10), temos que $m \underline{\text { não }}$ é divisível pelos primos $p_{1}, p_{2}, \ldots, p_{n}$ porque sobra resto 1.

12. Todo número inteiro [8] maior do que 1, ou é primo, ou pode ser escrito como um produto de primos (número composto).

13. De (9), sabemos que $m>1$.

14. De (12) e 13), temos dois casos:

(a) Caso 1: $m$ é primo;

(b) Caso 2: $m$ é um produto de primos.

15. Caso 1: suponha que $m$ seja primo.

16. De (8) e (9), $m=p_{1} p_{2} p_{3} \ldots p_{n}+1$ é maior do que todos os primos.

17. Como $m$ não é divisível pelos primos $p_{1}, p_{2}, \ldots, p_{n}$ (11), então $m$ é primo. 
18. (17) contradiz (8).

19. Caso 2: suponha que $m$ seja um produto de primos, $m=p q$.

20. $m$ é divisível pelo número primo $q$.

21. (11) e (20) levam a uma contradição.

22. A suposição (7) levou a um absurdo para os casos 1 e 2 , que são os únicos casos possíveis.

23. Portanto, existem infinitos primos.

\section{Considerações Finais}

24. Mostramos, passo a passo, que existem infinitos primos.

\section{Ciência Aberta}

O arquivo latex para este artigo, juntamente com outros arquivos suplementares, estão disponíveis em [9]. Seja coautor(a) deste artigo, envie sua contribuição para mplobo@uft.edu.br.

\section{Consentimento}

25. Todos os autores concordam com [10]. 


\section{Referências}

[1] Velleman, Daniel J. How to prove it: A structured approach. Cambridge University Press, 2019.

[2] Warner, Steve. Pure Mathematics for Beginners. GET 800, 2018.

[3] Warner, Steve. Abstract Algebra for Beginners. GET 800, 2018.

[4] Lobo, Matheus P. "N E 2 Elevado a N Menos 1 Não Primos." $O S F$ Preprints, 23 Jan. 2021.

https://doi.org/10.31219/osf .io/k67em

[5] OJMP Brasil. "Fundamentos da Matemática".

https://ojmpbr. wordpress. com/fundamentos-da-matematica

[6] Lobo, Matheus P. "Matemática Minimalista: Menos É Mais." OSF Preprints, 18 Oct. 2020.

https://doi.org/10.31219/osf.io/pey6z

[7] Lobo, Matheus P. "Matemática Zero." OSF Preprints, 1 Oct. 2020. https://doi.org/10.31219/osf .io/dgsf2

[8] Lobo, Matheus P. "Para Que Servem Os Números?." OSF Preprints, 8 Oct. 2020. https://doi.org/10.31219/osf.io/tyn7k

[9] Lobo, Matheus P. "Open Journal of Mathematics and Physics (OJMP)." OSF, 21 Apr. 2020.

https://doi.org/10.17605/osf.io/6hzyp

[10] Lobo, Matheus P. "Simple Guidelines for Authors: Open Journal of Mathematics and Physics." OSF Preprints, 15 Nov. 2019.

https://doi.org/10.31219/osf .io/fk836 


\section{Colaboração Matemática Aberta}

Matheus Pereira Lobo (autor principal, mplobo@uft.edu.br) $)^{1,2}$ https://orcid.org/0000-0003-4554-1372

Piotr Trzesniak ${ }^{3}$

http://orcid.org/0000-0002-2833-1923

${ }^{1}$ Universidade Federal do Tocantins (Brasil)

${ }^{2}$ Universidade Aberta (UAb, Portugal)

${ }^{3}$ Programa de Mestrado Profissional em Gestão Pública, Universidade Federal de Pernambuco (Brasil) 